\title{
INTENTIONS FOR MOBILITY OF THE NEXT HEALTH WORKFORCE GENERATION (COMPARATIVE STUDY AMONG BULGARIAN AND GERMAN STUDENTS IN THE MEDICAL UNIVERSITY OF VARNA)
}

Vanya Asenikova ${ }^{1}$, Elena Ignatova ${ }^{1}$, Petya Sarkizova ${ }^{1}$, David Westerdorf ${ }^{2}$, Sven Eger $^{2}$, Aline Breidung ${ }^{2}$, Maria Rohova ${ }^{3}$, Todorka Kostadinova ${ }^{3}$, Nikolina Radeva ${ }^{4}$

${ }^{1}$ Master Programme in Healthcare Management, Faculty of Public Health, Medical University of Varna

${ }^{2}$ Master Programme in Medicine, Faculty of Medicine, Medical University of Varna

${ }^{3}$ Department of Health Economics and Management, Faculty of Public Health, Medical University of Varna

${ }^{4}$ Department of Disaster Medicine, Faculty of Public Health, Medical University of Varna

\section{ABSTRACT}

INTRODUCTION: The migration of young health professionals is an important issue for the European health systems. If it is only temporal or circular migration, it could be beneficial for both receiving and source countries; but in case of permanent emigration, it could be interpreted as loss of human capital and loss of investments in education and specialisation. The aim of this study is to investigate intentions for mobility of students in health sciences.

MATERIALS AND METHODS: The study emphasises on the qualitative research - in-depth interviews with medical students. The interviews are conducted among Bulgarian and German students in Medicine, Dental Medicine, Nursing Care, Midwifery and Healthcare Management at the Medical University of Varna.

RESULTS AND DISCUSSION: The results from the in-depth interviews indicate that almost half of the Bulgarian students prefer to specialise and work in other European countries (Germany, UK, etc.). The preferred destinations for the German students are Scandinavian countries, Switzerland, Austria and the USA. Regardless of nuances in the replies, all of the respondents state the better payment as a reason for mobility. Most of the students share a desire to return and practise their profession in their country of origin.

CONCLUSION: The results from our study show that the motivation for migration is similar both for Bulgarian and for German students. The intentions of the students indicate high migration potential in the future. However,

Address for correspondence:

Maria Rohova

Faculty of Public Health

Medical University of Varna

55 Marin Drinov St

9002, Varna

BULGARIA

e-mail: mariarohova@abv.bg

Received: May 19, 2017

Accepted: June 23, 2017 the results predict also increased trends towards return or circular migration.

Keywords: mobility, migration, students, health professionals 
Intentions for Mobility of the Next Health Workforce Generation (Comparative Study among Bulgarian and German Students ...

\section{INTRODUCTION}

The migration of health professionals within and between countries is a growing phenomenon worldwide. This migration affects provision of services, quality of care, and distribution of staff across administrative units and countries (2). Health workers migrate from developing or less developed to developed countries to improve their economic or social situation immediately or for the purpose of career development (6). These outflows (permanent emigration of health professionals) are usually associated with the so-called medical "brain drain", which causes the unique problem of severe workforce shortages in source country's health systems. The permanent departure of skilled labour might deplete the human capital of sending countries, thus reducing the possibility for economic growth and raising the level of inequalities and poverty in those countries (5). Because of this, the international migration of health workers has become one of the major features on the health policy agenda.

The migration of young health professionals is an important concern. However, it cannot be interpreted unilaterally - the new economics of brain drain theory accept both the beneficial and detrimental effects on the country of origin (1). If it is only temporary or circular migration, it could be beneficial for both the receiving and the source countries, as well as for health professionals - the so-called "triple win situation". Return migration is one of the sources of "brain gain" - the highly skilled migrants return home and apply the knowledge and skills acquired during their stay abroad $(3,7)$. But in case of permanent emigration it could be interpreted as loss of human capital and loss of investments in education and specialisation.

Although the intentions for mobility are not really migration, they could provide important information about the future trends. In this regard, our study aims to give answers of the following questions:

$\diamond$ What do the intentions of the new generation indicate - a brain gain or a brain drain?

$\diamond$ Which are the driving factors for mobility of the next generation of health professionals?

$\diamond$ What are the stick factors in the country of origin? $\diamond$ Could we expect different mobility patterns for the next $10-15$ years?

\section{MATERIALS AND METHODS}

The study combines qualitative and quantitative methods but emphasises on the qualitative research - in-depth interviews with medical students. The general idea of this approach is to gather qualitative information about the personal motives and the decision-making process concerning the intentions for mobility of the next health workforce generation.

The study was conducted at the end of 2015. The sample includd 78 students in Medicine, Midwifery, Nursing Care and Healthcare Management at the Medical University of Varna, Bulgaria. Of the total, 48 were Bulgarians and 30 were German citizens studying in Bulgaria.

The inquiry included questions about general patterns of migration in Bulgaria and in Germany respectively and about the attitudes of the respondents toward mobility. More important for our study were the intentions of the students to specialise and/ or to work abroad after graduation, the reasons for these intentions and the so-called stick factors that could retain them in the country of origin.

\section{BACKGROUND}

In Bulgaria, immigration is negligible in its size and importance and emigration is the prevailing $\mathrm{mi}-$ gration process. Bulgaria is a predominantly sending country.

Since 2007 (Bulgarian accession to the European Union), many Bulgarian doctors have left the country, and more and more young health professionals emigrate immediately after their graduation. The immigration of health professionals in Bulgaria is not a significant process.

Official information concerning the mobility of health professionals in Bulgaria is missing. Possible landmark is the number of issued certificates of conformity to health professionals who want to seek professional realisation abroad. Information in the media points out that in 2015, the Bulgarian Medical Union issued 505 certificates to doctors who wanted to work or specialise abroad. For the majority of Bulgarian doctors the preferred destination country is Germany followed by the United Kingdom and Ireland. Approximately the same is the number of the 
Vanya Asenikova, Elena Ignatova, Petya Sarkizova et al.

certificates issued to nursing professionals. However, according to some unofficial estimation, the number of nursing professionals who yearly leave the country is twice as high. The main reason is the level of remunerations in Bulgaria.

The desire to work abroad for German citizens is regular and prominent. Since 2005, the outflows have been significantly higher than the inflows. In 2014, approximately 150000 citizens departed from Germany (4).

One of the major problems in Germany is the medical universities' admission and limited places for specialisation and training. Currently, almost 88 000 medical students are enrolled in German universities but there are much more applicants than available university places. Therefore, studying abroad is getting more and more attractive.

\section{RESULTS AND DISCUSSION}

Because mainly young doctors leave Bulgaria, the health system may lose part of its best stock of young human resources together with its innovative capacity. This also limits the opportunities for generation replacement in the system.

According to the results of our study, the push factors in Bulgaria can be summarised as follows:

$\diamond$ low income;

$\diamond$ organisation of the health system;

$\diamond$ lack of opportunities for career development;

$\diamond$ insufficient places for specialisation and training problems;

$\diamond$ unstable economic situation.

The most of the interviewees share the opinion that there are difficulties for their future professional development in Bulgaria. They found difficulties with specialisation, organisation and frequent changes in the health system. All of them think that the health professionals' work is not adequately evaluated.

Regardless of the nuances in the replies, all of the respondents state as a reason for emigration the desire for better payment. Other mentioned factors are education and training opportunities, social status, social relations and standard of living, and better economic situation. Work abroad could be of benefit for working conditions, career development, living conditions and scientific activities, as well as it pro- vides better opportunities for the family. These statements together with the dissatisfaction with career development, remuneration and working conditions in Bulgaria, suppose a significant emigration potential among Bulgarian health professionals.

The factors motivating German students to leave their country are similar. The interviewed state several reasons to leave Germany:

$\diamond$ overwork;

$\diamond$ higher salary;

$\diamond$ career development;

$\diamond$ working conditions.

The German students are aware that these reasons are a manner of subjective impression in comparison to other European countries. It is not surprising that the pull factors in the receiving country are related to the push factors in Germany. In general, less work hours is not the only reason that led graduated physicians to migrate. The leading causes for emigration from Germany are better working conditions and higher salaries. Further reasons include lower taxes and better standard of living.

Around one third of the 48 Bulgarian students shares desire to work or to specialise abroad. According to the survey, the most preferred destinations are countries with stable economic development and modern health systems. More than a half of the students think of specialisation abroad, but with small exceptions, they all share a desire to return and practise their profession in Bulgaria. Some of them believe that the specialisation or temporary work abroad are a good start for career development in Bulgaria.

The majority of the German students, mainly from the 2nd and 4th academic year want to work abroad. For emigration, the German students would mainly prefer Switzerland, Scandinavian countries and the USA. This reflects the basic German migration trends.

The essential reason for specialisation abroad is the desire to have less work hours in their future career and to maintain a better balance between work and private life. Other reasons for specialisation abroad are the possibility to learn a new language and cultural experience. Many German students are convinced that in a globalised world the English programme could be beneficial for their further career 
development. Preferred destinations for specialisation are Switzerland and Austria.

When we asked our colleagues if they would come back to practise in Bulgaria after their specialisation abroad we investigated the importance of the stick factors. More than a half of the respondents would like to gain knowledge, skills and professional experience abroad but they want to return to Bulgaria - the so-called return migration, which could be interpreted as brain gain for the country. The family and social ties become more important incentives than the level of remuneration and the living standard. In addition to these reasons, the respondents listed also patriotism, beautiful nature and favourable climate as reasons for staying in Bulgaria.

The majority of Bulgarian students believe that if they go abroad it would be better for their career development. Only six of the respondents expected good career development in Bulgaria. However, there are also some positive changes in Bulgaria, which can be viewed as opportunities for the future. We hope that these positive trends will have a positive impact on the health system and on retaining of health professionals.

For the German students the main stick factors can be summarised as follows:

$\diamond$ family and friends;

$\diamond$ language barriers;

$\diamond$ fear of a unknown situation in the new country.

However, the good specialisation in Germany and the social environment are factors to stay in the country after graduation. All of the interviewed German students think that training, specialisation or temporary work abroad are a good start for their career. Many think that for students who want to start a professional career, nowadays it is essential to work abroad. Regardless of the motivation to study and specialise abroad, the majority thinks that they would return to Germany one day. We also have discussed with German students the probability to stay in Bulgaria after their graduation. The majority would rather return to Germany or go to another country.

\section{CONCLUSION}

The mobility of health professionals is a worldgrowing phenomenon, which affects not only developing or middle-income countries (as Bulgaria) but also developed countries (such as Germany). The re- sults from our study show that motivation for migration is similar for both Bulgarian and German students. The intentions of the students indicate high migration potential. However, the results predict also increased trends towards return or circular migration, which can be interpreted as beneficial for both receiving and sending countries.

A strategy on the migration of healthcare professionals is non-existent in Bulgaria although efficient measures are in demand. The measures should not be restrictive but stimulating the employment and career development and should help enhance the image of the medical profession. The policy on human resource development should guarantee opportunities for maintaining and increasing the level of qualification, improvement of remuneration and modern equipment. The policy has to be focused on more adequate assessment of the health professionals' work.

\section{REFERENCES}

1. Boncea I. Turning brain drain into brain gain: evidence from Romania's medical sector. Procedia EconFinanc. 2005; 20:80-7. doi: 10.1016/ S2212-5671(15)00050-7

2. Diallo K. Data on the migration of health-care workers: sources, uses, and challenges. Bull World Health Organ. 2004; 82(8): 601-7. doi: 10.1590/ S0042-96862004000800010

3. Docquier F. Brain drain and inequality across nations. IZA Discussion Papers, No. 2440, 2006. Available from: http://nbn-resolving.de/ urn:nbn:de:101:1-2008071751.

4. D_Statis, Statistisches Bundesamt, Bevoelkerung, Wanderungen. Accessed: 15.03.2016. Available from: https:/www.destatis.de/DE/ZahlenFakten/ GesellschaftStaat/Bevoelkerung/Wanderungen/Tabellen/WanderungenDeutsche.html.

5. Forcier MB, Simoens S, Giuffrida A. Impact, regulation and health policy implications of physician migration in OECD countries. Hum Resour Health. 2004; 2:12. doi: 10.1186/1478-4491-2-12

6. Rutten $\mathrm{M}$. The economic impact of medical migration: a receiving country's perspective. Rev Int Econ. 2009; 17(1). doi: 10.1111/j.1467-9396.2008.00798.x

7. Stark O, Fan S. Losses and gains to developing countries from the migration of educated workers: an overview of recent research and new reflections. CMR Working Papers, No. 20/78, 2007. 